\title{
Optimization of Enterprise Financial Management and Decision-Making Systems Based on Big Data
}

\author{
Shaomin Ren \\ School of Accounting, Sias University, Xinzheng 451199, China \\ Correspondence should be addressed to Shaomin Ren; 14960@sias.edu.cn
}

Received 24 November 2021; Revised 10 December 2021; Accepted 31 December 2021; Published 20 January 2022

Academic Editor: Miaochao Chen

Copyright (C) 2022 Shaomin Ren. This is an open access article distributed under the Creative Commons Attribution License, which permits unrestricted use, distribution, and reproduction in any medium, provided the original work is properly cited.

Based on information asymmetry theory, principal-agent theory, and risk management theory, this paper analyzes the mechanism of the impact of big data on financial decision-making, analyzing four dimensions: how big data enhances the information base for forecasting, how big data improves the relevance of decision-making, how big data builds new competitive advantages, and how big data promotes dynamic decision-making. Secondly, through the analysis of specific implementation cases of enterprise big data in financial decision-making, we focus on the real problems faced in management and the effect of solving problems through big data platform. The enterprise realizing the integration of business and finance not only can better lead business expansion, but also can improve the management level within the enterprise, which is conducive to the improvement of core competitiveness. The integration of industry and finance is essentially achieved through the application of various financial management modules to the business operations of enterprises, including budget management, capital management, fixed asset management, and financial accounting. If we want to implement the whole process of financial integration, it is impossible to achieve this manually, and we must first build a powerful information system as a guarantee. Under the guidance of theories of information asymmetry, stakeholders, and management information systems, Internet finance enterprises should build their own integrated business finance system based on the demand for business finance integration in the Internet finance industry, to enhance the matching of business finance data of Internet finance enterprises, improve the efficiency of enterprise management, and realize business finance integration. Finally, through the research of this paper, we hope to provide reference for other similar enterprises to apply big data for financial decision-making. Through the application of big data, higher economic benefits are achieved in procurement management, production control, capital budget, and investment decision compared with the previous ones. It is concluded that in the era of big data, massive data can be used to serve enterprise decision-making in depth, which can break the business and financial barriers, improve the efficiency and quality of decision-making, optimize the organizational structure and personnel, and enhance the prediction and early warning capability. The application of big data tools has become the key to assisting financial decision-making and enhancing enterprise value.

\section{Introduction}

The impact of big data on financial management is profound and revolutionary, specifically in the following ways: first, big data makes the processing of financial information more difficult and the boundaries of information very blurred; second, big data changes the breadth and depth of financial management; third, big data improves the efficiency of financial management significantly; fourth, big data enhances the risk control capability of financial management. In short, giving full play to the advantages of big data can make the probability of systemic financial risks of enterprises decrease, while the prediction of the future is more accurate [1]. It is not easy to comprehensively promote the application of big data in financial management decisions. In reality, there are many obstacles, such as outdated concepts of financial managers, refusal to innovate, poor internal information sharing, poor financial risk awareness, weak control ability, and insufficient control ability of financial information technology personnel [2]. It is not easy to comprehensively promote the application of big data in financial management decision-making. There are many obstacles. For example, 
financial managers have outdated concepts, repel innovation, and are unwilling to invest in information; internal information processes are imperfect; and information sharing is poor. For example, Alibaba has listed the information resources brought by the era of big data as another factor of production after labor, land, and capital, and its launch to build a cloud computing platform through "Ali cloud" provides core technical support for the construction of the group's big data industry chain [3]. Big data brings important information resources and has become an important asset for enterprises to obtain business opportunities, develop markets, reduce costs, increase revenue, and innovate business models. Traditional data management and data analysis techniques are difficult to effectively tap, which can easily lead to the inability to discern the value of information and the increased difficulty in taking and using information. Moreover, the traditional decision-making relying on experience will become history, and the effect of decision-making will be different due to the different degrees of difficulty in obtaining market information by specific information channels [4].

At present, the technical level of big data is still in its infancy, and investing a lot of human, material, and financial resources may not bring direct benefits in the short term, so strengthening the decision-making level's understanding of big data is the most critical step. From the current decision analysis system and big data platform implemented by individual listed companies and Internet enterprises online, fully tapping the value of data can indeed greatly improve the efficiency and quality of decision-making [5]. This paper takes an actual case as an entry point while using the group financial big data platform to explore how new technologies can assist managers in better strategic management, decision support, risk identification, control, etc. The case is analyzed and studied to identify the elements and change paths of the impact of big data on financial decision-making and further enrich the theoretical granularity [6]. The specific application of big data is not perfect. At the present stage, the specific application of financial decision system is only applied in large Internet enterprises. Although most enterprises have realized that data mining online analysis is the future trend, they are still in a wait-and-see state. In view of this, we must solve the problems in management as the guidance, from blueprint design, technical architecture, front-end display and other stages to reveal the big data in financial decision-making to improve organizational efficiency, reduce costs, consolidate the advantages of enterprise core competitiveness, to provide important reference value for practical research.

The management accounting information system constructed is unsystematic and decentralized, and the decentralized system modules have their functions and cannot carry out enough data sharing and assist in a solution where everyone benefits; therefore, the management accounting information system does not play its role completely, the role played by most enterprises' management accounting information system at present is mainly accounting role, and its management accounting role is not well applied. In the process of business management, enterprises do not make use of the functions of management accounting and do not use management accounting information systematically; they only use management accounting tools in some modules of management activities. Therefore, enterprises must incorporate management accounting tools or methods into the relevant management aspects of the enterprise and plan for the construction of management accounting information system, to finally realize the role of management accounting planning, control, management, and decision-making, which will greatly enhance the competitiveness of enterprises through the construction of big data management information system.

\section{Current Status of Research}

Big data, along with the rapid development of the Internet and information technology, has generated exponential growth in the amount of information, covering various fields and business processes, specifically in financial decision-making, which has broken through the original scope and boundaries [7]. From the available literature research, big data is mainly applied to cost control, comprehensive budget, financial analysis, capital management, investment decision-making, etc. With the integration of big data and new technologies such as cloud computing and blockchain, big data has more room for financial decision-making, and the decision result will be different for the same decision object in time and space [8]. From the perspective of the path of decision-making activities, the impact of big data on financial activities and financial relationships determines the effect of financial decision-making [9]. The impact of the big data value chain on forecasting, decision-making, control and evaluation, and stakeholders is studied and analyzed; the challenges faced by big data in the specific application process are explored; and a new path for financial management innovation is proposed. In terms of decisionmaking operations, big data is reflected in precision, integration, and correlation for financial decision-making. Cost control through big data technology is studied, and enterprises get cost data through multiple channels and analyze the material usage standards according to them to meet the actual needs. Structured and unstructured data such as payroll details, inventory documents, and manufacturing costs are shared in the system [10]. The role of big data in comprehensive budgeting is studied, and it is proposed that in the past, comprehensive budgets were built based on the experience of business managers plus static data, which lacked adaptability, and big data made up for the lack of sampling means [11]. The financial analysis and business model innovation in the context of big data are studied, and it is pointed out that the goal of financial analysis is more strategically oriented, which requires enterprises to do corresponding business model innovation.

Starting from the basic theory of management accounting, the analysis of management accounting information system has a nonnegligible positive effect on the 
company's financial system and information platform construction, and by studying specific implementation strategies, corresponding suggestions are made for the company's modern information development system; for example, the company can use the financial sharing model to develop cloud computing [12]. It is easy to cause the value of information to be indistinguishable, making it more difficult to choose and use information. Furthermore, traditional decision-making relying on experience or "brainstorming" will become history. Specific information channels and the difficulty of obtaining market information will result in different effects of decision-making. It is pointed out that in the process of building information systems in enterprises, the responsibilities of all aspects of enterprises should be clarified to further improve the profitability of enterprises [13]. It is believed that through the construction of the internal information platform of the enterprise, the daily management of the enterprise is made borderless, and the employees can directly feed back relevant information to the leaders of the enterprise [14]. It is believed that in the process of development of enterprise accounting information technology, enterprises face great development opportunities and at the same time face the risks brought by the market.

To further improve the efficiency of enterprise operations, most enterprises have reconstructed and improved their traditional information systems following future business development requirements and trends in the development of enterprise information systems, gradually associating traditional automated accounting information systems with the business of enterprise operations, and integrating enterprise accounting information processing with various businesses of the enterprise through an integrated framework. Traditional accounting measurement is limited to monetary measurement, and numerous economic activities cannot be measured in monetary terms during actual business operations, for example, the number of customers developed by business personnel and the execution of sales tasks. Fundamentally, traditional accounting information based on the monetary measurement is only a subset of business activities, and this information can hardly provide decision support for managers. Therefore, big data management accounting information systems must be able to provide processing functions for both financial and nonfinancial information.

\section{Optimization Analysis of Enterprise Financial Management and Decision-Making System Design for Big Data}

3.1. Financial Management and Decision-Making System Design for Big Data. An intelligent financial system is a system that combines artificial intelligence and financial management to be utilized, and this system can be said to be an extension of the development system of management accounting informatization [15]. Management accounting is an important branch of current accounting development, and informatization is a technical means for the successful realization of management accounting concepts and methods. Guided by solving problems in management, in-depth analysis and comparison of effects reveal that the application of big data in financial decision-making plays an important role in improving organizational efficiency, reducing costs, and consolidating the core competitiveness of enterprises. The intelligent financial system can interconnect the business activities and financial activities of the enterprise, monitor each link in real time, and provide a more reasonable and efficient decision-making intelligent financial system to the internal and external managers of the enterprise by displaying more intuitive data. Enterprises pay much attention to internal control to be able to better reduce and resolve risks, but the excessive rigor of internal control can easily lead to duplicate approval of a matter in procurement, payment, withholding, contracts, etc.

The approval process can be reduced with the help of intelligent finance to improve the efficiency of financial management. If you want better financial management and decision-making with the help of financial information, you must record and organize the financial information promptly, and only with specific control of the information can you provide more realistic information to the users of financial statements. In addition, customers can use the financial statement information to obtain timely information about the development of the enterprise, to facilitate the understanding of customers, and play a certain role in supporting the company's decision-making through quantitative decision-making.

The key point of this type of software is to solve the core business processes of enterprises, which is implemented first in manufacturing enterprises and then gradually in other industries. Due to the summation of many years of application practice of users, after a long period of development and improvement, the built-in data models and algorithms of such software are powerful, sound modules; rigorous structure; and process transformation. Furthermore, due to a long time of launch, more downstream service providers can provide consulting and technical services. This model of software has its characteristics according to the different segments of the market; generally serves only a few specific industries, a specific scale of enterprises, or a specific business model of enterprises; and cannot provide full industry coverage, as shown in Figure 1.

To further improve the efficiency of enterprise operations, most enterprises have reconstructed and improved their traditional information systems according to future business development requirements and trends in the development of enterprise information systems, gradually associating traditional automated accounting information systems with the business of enterprise operations and integrating enterprise accounting information processing with various businesses of the enterprise through an integrated framework [16]. Any enterprise accounting personnel in the process of accounting information processing should be based on the actual business of that enterprise; therefore, the big data management accounting information system is designed based on the 

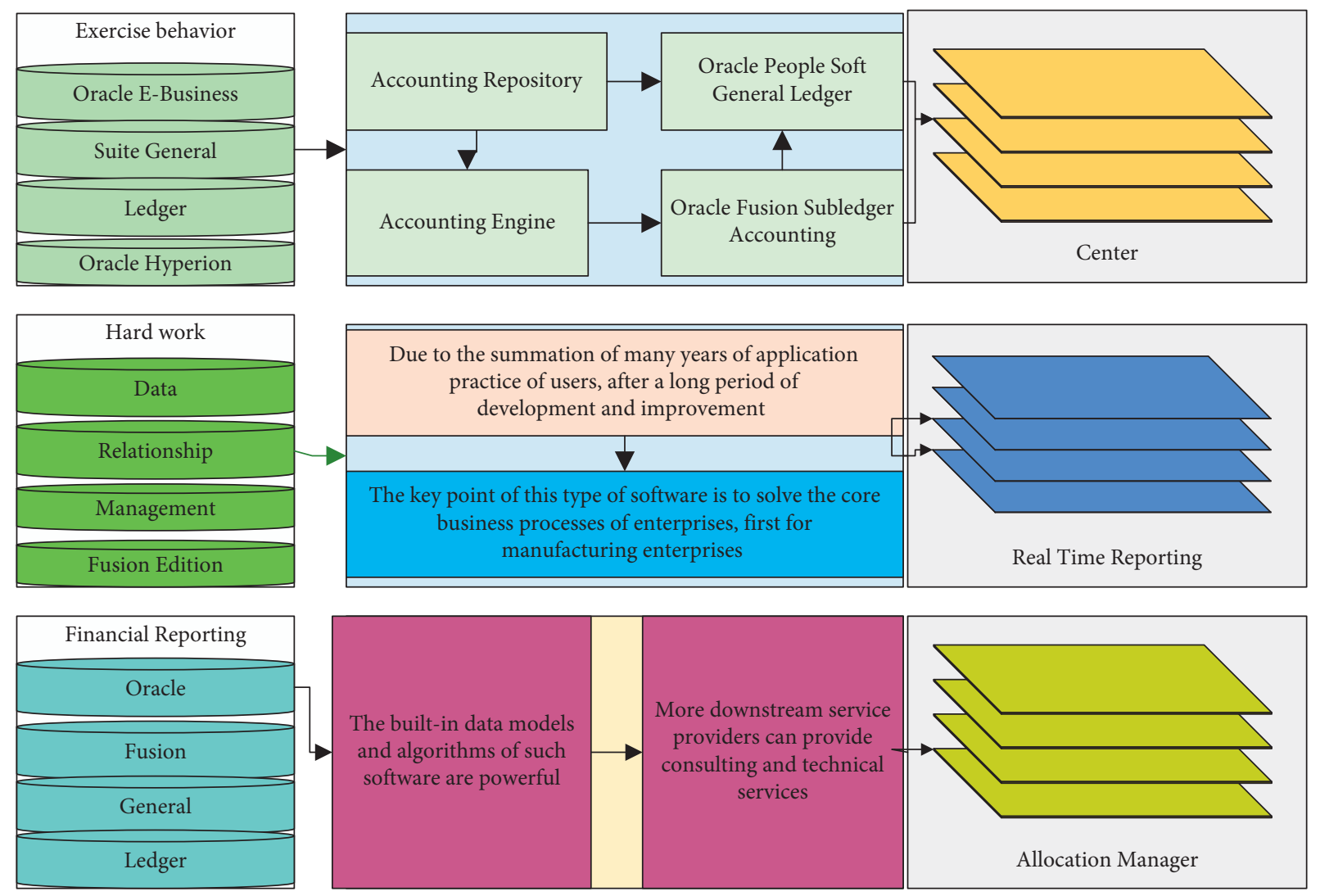

FIGURE 1: Framework for financial management and decision-making system for big data.

business rules of that enterprise, so that it helps to timely find out whether the enterprise financial personnel in the process of accounting information processing is against the established rules, and the enterprise can take corresponding measures in time to correct problems. At present, most corporate management accounting information systems play a major role in accounting, and their management accounting functions have not been well applied. In the process of operation and management of enterprises, the functions of management accounting are not used, and management accounting information systems are not used systematically.

$$
\begin{aligned}
\mathrm{tab} & =\operatorname{tab}_{M} \cap \mathrm{tab}_{R}, \\
\rho & =\lim _{\Delta x \rightarrow 0} \frac{f(x-\Delta x)-f(x)}{M(x)+\Delta x} .
\end{aligned}
$$

The data-sharing platform includes data access, cleaning, conversion, and loading, where data access is to access data from various storage media and identify data in various formats; data cleaning is mainly data verification, filtering, consistency comparison, noise removal, incomplete data and error rejection, etc.; data integration and conversion refer to data conversion mapping, data splitting and merging, dictionary table association finding, standardization processing, error exception processing, etc.; data loading refers to loading the data into the target repository and ensuring the accuracy and reliability of the data. After these four steps of data processing, the data warehouse is finally formed, which contains different data marts inside.
It is mainly based on the data layer and data processing layer technology directly generated by the financial and decision-making analysis portal. On this basis, data indicators are also added to drill down layer by layer and penetrate each other, with the purpose of stimulating human intelligence and facilitating coherent thinking and effective thinking and judgment within the analysis portal through, for example, charts, tables, text, dashboards, and indicators. It concretizes and visualizes the group's management data, comprehensively realizing the integrated enterprise performance evaluation and control program of the management process of pre-prediction, mid-event control, and postevent analysis. Through benchmarking and early warning, it reveals problems in enterprise operation; through intelligent risk identification, risk identification and reporting, and executive feedback, it realizes real-time comprehensive risk interactive control and management.

$$
\begin{aligned}
Y & =\sum_{i j=1}^{m} \frac{n_{i j}+n_{i j \min }}{n_{i j \max }-n_{i j}} W_{i j}, \\
\overrightarrow{\mathrm{ML}} & =\sum_{0}^{n} m^{n} l^{2} .
\end{aligned}
$$

Cybernetics is the discovery of control laws and design of control rules based on the study of system theory, to achieve specific goals, and the use of information as the key medium to make the management object operate according to the expected goals [17]. Therefore, information feedback is 
particularly important in management accounting information systems, when the information generated by the activities of the controlled end is sent to the control system after processing and transformation and then output to the controlled end so that effective control can be carried out back and forth. Management accounting information system should follow the theory of control, divide the overall goal of the enterprise in each enterprise management subject, and set up information interaction terminal and information transmission channel for each management subject so that each management subject can feed back information to the management accounting information system in real time and ensure the controllability of each subject/object in the enterprise.

$$
\begin{aligned}
M^{*} & =\underset{x \in \Omega_{x}}{\operatorname{argmax}}\left\{\sup \left|b\left(\mathrm{x}^{3}\right)+W^{T} S\left(x^{2}\right)\right|\right\}, \\
M(x) & =w_{2} \sigma^{2}\left(w_{1} x_{1}\right), \\
J & =M\left(x^{2},\left\{w_{i}^{2}\right\}\right)-x .
\end{aligned}
$$

The main objective is to analyze the problems in the management of enterprises in the current business process from various aspects, which helps enterprises to establish scientific and effective development decisions, to enhance the market competitiveness of enterprises. Comprehensive budget management should be fully based on the basic realities of the enterprise, combined with the business objectives of the enterprise to improve the internal control means to ensure that the enterprise business activities are in a healthy and good state. In the process of work promotion, business leaders should actively adjust in the light of the actual situation and the problems exposed and ensure that the budget data calculated by the analysis can be unified with the real factors. All this analytical work will be the basis for adjusting development decisions, helping to achieve the business goals of the enterprise, and expanding its comprehensive strength. Achieving the strategic business objectives of the enterprise is an important part of the budget management work; the enterprise needs to continuously optimize the organizational structure and make full use of its internal resources to ensure scientific and effective strategic planning. Through budget management, the functional positioning of each department within the enterprise is clarified, and an effective and scientific communication mechanism is established between each department to create a good working atmosphere and better achieve the business objectives of the enterprise, as shown in Figure 2. Combined with the above definition, the intelligent financial system refers to the collection of subjects and processes involved in the intelligent development of management accounting information systems.

In the digital economy, the value creation model has evolved from the more monolithic value chain model to three value creation models: value chain, value network, and value store. The traditional value chain model mainly describes not only the process of production and thus value creation of tangible goods by traditional or vertically integrated manufacturing firms, but also the production and thus value creation of intangible goods (e.g., movies, music, games) through linear manufacturing processes. The value network model relies on digital technology because it serves as a medium to facilitate exchange relationships between end users and to transfer the offline value network to online one, enhancing the ease of information exchange among users, and it differs from the sequential conduct of activities in a value chain in that activities in a value network are simultaneous and cross-cutting.

$$
\begin{array}{r}
P=\min _{P} \sum_{i=1}^{n} \frac{1}{2} x_{i}+X_{P_{i} 2}^{2}-\chi P_{2,1}, \\
Q_{L}(w)=\lim _{n \longrightarrow \infty} \sum_{i, j=1}^{n} \frac{1}{i j}\left(P_{i}+P_{j}\right)^{2} P_{i j}^{3} .
\end{array}
$$

ERP centralization makes group companies more efficient and accurate in handling internal transactions. Before the implementation of the ERP centralization project, most of the group's subordinate units were developed and used their independent financial systems; the group needs to integrate internal transaction data is required to carry out reconciliation of transactions in each company to get the exact data [18]. By integrating the financial and accounting information platform of each subordinate unit into one or several sets of unified systems, the ERP centralization project can query the business transactions between the head office or branch and subordinate units and the business transactions between subordinate units in real time, which effectively improves the efficiency of management, statistics, analysis, and accounting of internal business and financial data of each unit based on ensuring the accuracy and effectiveness of basic data.

3.2. Financial Management and Decision Design. First, it allows on-site business finance personnel to participate in front-line operation activities, such as project costing, analysis of enterprise operating costs, analysis of and the completion of production and operation index budgets, being effectively integrated into the business and helping to promote the refinement of enterprise management. Second, the establishment of the shared service platform allows the original complex financial work to be decomposed, lowering the standard of job competency. Originally, the basic requirements for recruiting financial personnel were a bachelor's degree, accounting or financial management or other related majors, and preferably a corresponding junior or intermediate title. Finally, financial sharing provides a new mode and means of financial control, centralizes the company's financial management, strengthens the supervision of branches, and effectively reduces the financial risks caused by excessive financial authority of branches. The financial sharing service platform provides the possibility that the group's finance realizes the value of data in the information era, and provides an opportunity for the 


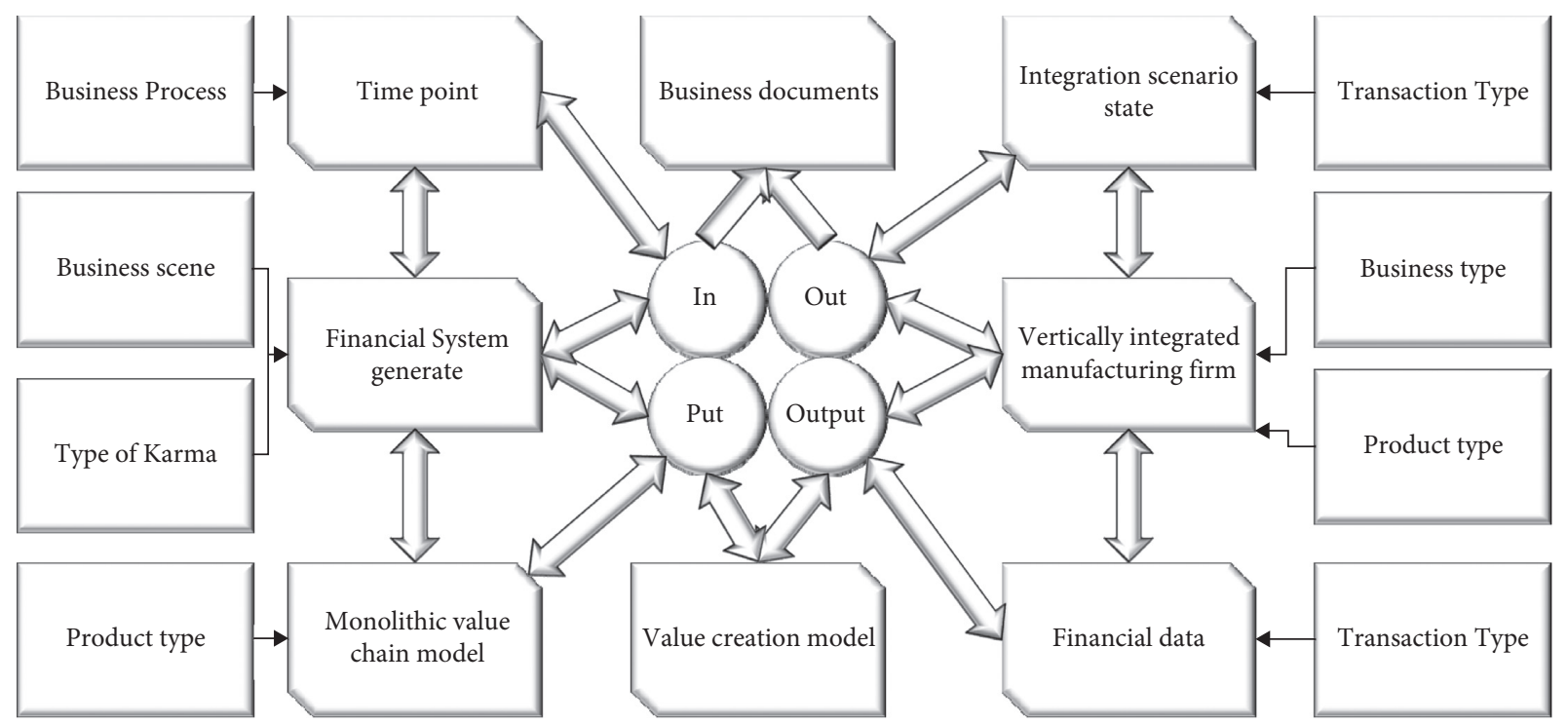

Figure 2: Overall framework of an integrated BFAS.

group's finance to further transform and develop. To enhance the market competitiveness of enterprises, comprehensive budget management should be fully based on the basic facts of the enterprise, combined with the business objectives of the enterprise to improve the internal control methods of the enterprise, and ensure that the business activities of the enterprise are in a healthy and good state.

$$
\begin{aligned}
P_{i j}^{N} & =1-P_{i j}^{2}, \\
f^{n}(t) & =\lim _{h \longrightarrow 0} \frac{1}{h^{n}} \sum_{m=0}^{n}(-1)^{m}\left(\begin{array}{l}
n \\
m
\end{array}\right) f\left(t^{2}+m^{2} h^{2}\right) .
\end{aligned}
$$

The project team members are composed of the group's data management office and various business departments and developers. The group's data managers and developers are involved in the entire implementation process to ensure the smooth implementation of the solution. There are four types of enterprise organizations: vertical boundary, horizontal boundary, internal boundary, and geographical boundary [19]. The vertical boundary mainly refers to the management level within the organization, the horizontal boundary is mainly the boundary of different responsibilities and division of labor of departments at the same level, the external boundary is the boundary between the enterprise and upstream and downstream partners and the value chain, and the geographical boundary is based on the scale of the enterprise and the boundary of each division under globalization. The big data decision-making platform implemented by the group gradually breaks the above four boundaries; however, it does not eliminate the boundaries but emphasizes the organic and permeable nature of various organizational boundaries, so that information communication breaks the barriers of departments and professions to achieve the optimal allocation of enterprise resources and maximize the value.

$$
\begin{aligned}
F_{i}^{d}(t) & =\sum_{j \in K} \operatorname{rand}_{j} F_{i j}^{d}\left(t_{i j}^{2}\right), \\
G J_{i k}^{j i n t} & =\sum_{i=1}^{N} G_{j}^{j} j_{i k}^{j \text { int }}
\end{aligned}
$$

The traditional sense of aggregated analysis reports exposes the shortcomings of the management decisionmaking process, which is reflected in the huge volume of business data, the lack of targeting of a single report, and the lack of a comprehensive display, and other aspects. The big data decision-making platform is not a simple data extraction and aggregation but needs to exist in the form of data sets and management scenarios, aiming to provide powerful support for the refinement of group data and the precision of decision-making through data analysis and management scenarios, collect and integrate master data and indicator data from various systems of the enterprise, generate data mart, and facilitate the unified management of enterprise data by the information department. For the reusable master data, the relevant business data is cleaned uniformly to facilitate the unified call of the business system in the future. For indicator data, the storage structure is optimized to finally support the management of enterprise data and solve the problem of data silos. From the perspective of the company's data management system, the ultimate need is to achieve the comprehensive analysis and presentation of data from various business sectors. We should focus on the data of the business system, manually fill in the data as a supplement, extract and organize related indicators, let business departments participate in the process of data input and output, in order to promote the industrial and commercial departments to improve the relevant organization construction, assessment indicators are as shown in Table 1.

It was difficult to accept the new management model; moreover, the financial shared service center was in the early 
stage of creation and was still in the trial operation stage, so the management finally decided to extend the original performance appraisal system of the group and did not design a new appraisal method for the new financial management model brought by the financial shared service center [20]. The original appraisal index was relatively single, which could not effectively motivate the new organizational structure and was only an assessment of personnel, which could not show the business effect of the financial shared service center itself, and there were phenomena of low motivation and ineffective indexes for employees. The financial shared service center has centralized the accounting of funds, simplified the business departments, and reduced the overlapping and formalized departments in the past, saving the group's costs, which has formed a gap for some employees who think that state-owned enterprises are "iron rice bowls". Finally, the original performance appraisal system is no longer applicable and cannot reasonably quantify the new working model of the financial shared service center. It can also explain the process of creating value for intangible goods (such as movies, music, games) through a linear manufacturing process; the value network model depends on digital technology, because digital technology as a medium promotes the exchange relationship between end users.

Broadly speaking, the intelligent financial system, from a macro perspective, is led by the wide application of intelligent technology in the field of management accounting, based on the construction of information networks such as the Internet and the Internet of Things, with the development and utilization of management accounting information resources as the core, and the training of management accounting informatization talents, all of which cannot be carried out smoothly without the guarantee of policies, laws and regulations, and guidelines related to intelligent finance. Enterprises that have successfully used intelligence for financial management activities include apparel manufacturing enterprises, Internet enterprises, retail chains, and third-party payment enterprises. The application subject, as the core object in the intelligent financial system, cannot develop its intelligent financial system without external influences, such as relevant government authorities, industry associations, and big data platforms, so these organizations are also an integral part of the financial intelligent subject, as shown in Figure 3.

The financial shared service center centralizes fund accounting, simplifies business departments, and deletes previously overlapping and formalized departments. In this regard, the underlying network communication, intelligent perception, general intelligence engine, and other support systems have an important role. The intelligent perception system perceives the internal and external business activities of the enterprise and automatically completes the data collection work through the commonly used technologies such as barcode, optical character recognition, and radiofrequency identification; the network communication system uses the satellite network for information transmission and interaction sharing; the data management system focuses on the use of data mining and data warehouse to provide decision-makers with a basis for intelligent data processing; the intelligent engine system involves the reasoning engine, process engine, and accounting engine.

\section{Analysis of Results}

4.1. Performance of Financial Management and DecisionMaking Systems for Big Data. The financial sharing model is quite different from the traditional financial model. The company should provide the necessary daily training for the entry-level employees in conjunction with the actual service business of the platform, communicate with the employees regularly to understand their training needs in real time, and formulate an annual training plan that meets the financial sharing development trend and improves their work skills, which makes employees clear about their job responsibilities and understand the basic job content of other different positions. For the financial and technical staff of the platform, in addition to their skills, the training content should also include training on the overall platform organization and job division. Thus, the staff should improve their knowledge of the shared service model; realize that financial shared service is the cornerstone of financial management transformation; learn the advantages of this model during complicated work; and learn how to carry out standardized management, process reengineering, and specific application of information technology system in finance. The platform establishes systematic and regular training management so that all employees can realize their self-worth in their work.

There are three main application scenarios of intelligent financial benchmarking applications for group companies, which are industry benchmarking, budget benchmarking, and historical benchmarking. Budget benchmarking refers to the budget completion ratio, used to check the budget completion of the main financial indicators of the company and provide a basis for the company to formulate the budget in the next year. Historical benchmarking refers to comparing the value of current financial indicators with the value of indicators in the same period. Historical benchmarking can clarify whether the company has changed its main financial indicators in the same development scenario, and if the difference is large, it will find out whether the problem is caused by the operation or macro and industry changes. The other scenario is industry benchmarking, where the system has built-in industry indicator parameters for different industries and sizes for the last ten years. The system is classified according to the national economy industry classification standard while being divided into four scale levels: industry-wide, large-sized, medium-sized, and smallsized enterprises, and it covers nearly 30 industry indicators in five categories, namely, profitability status indicators, asset quality status indicators, debt risk status indicators, business growth status indicators, and supplementary indicators. The group's industry benchmarking function is not only reflected in the intelligent financial analysis report, but also fully reflected in the benchmarking with other reclamation enterprises in the same province managed by the Bureau of Reclamation. The indicators mainly include total 
TABle 1: Assessment indicators.

\begin{tabular}{lcc}
\hline Comprehensive index cost & Specific indicators & Weights \\
\hline Efficient management & The ratio of business processing unit cost management & 12 \\
Service management & Cash flow turnover rate & 14 \\
Innovation & Document processing efficiency & 18 \\
\hline
\end{tabular}

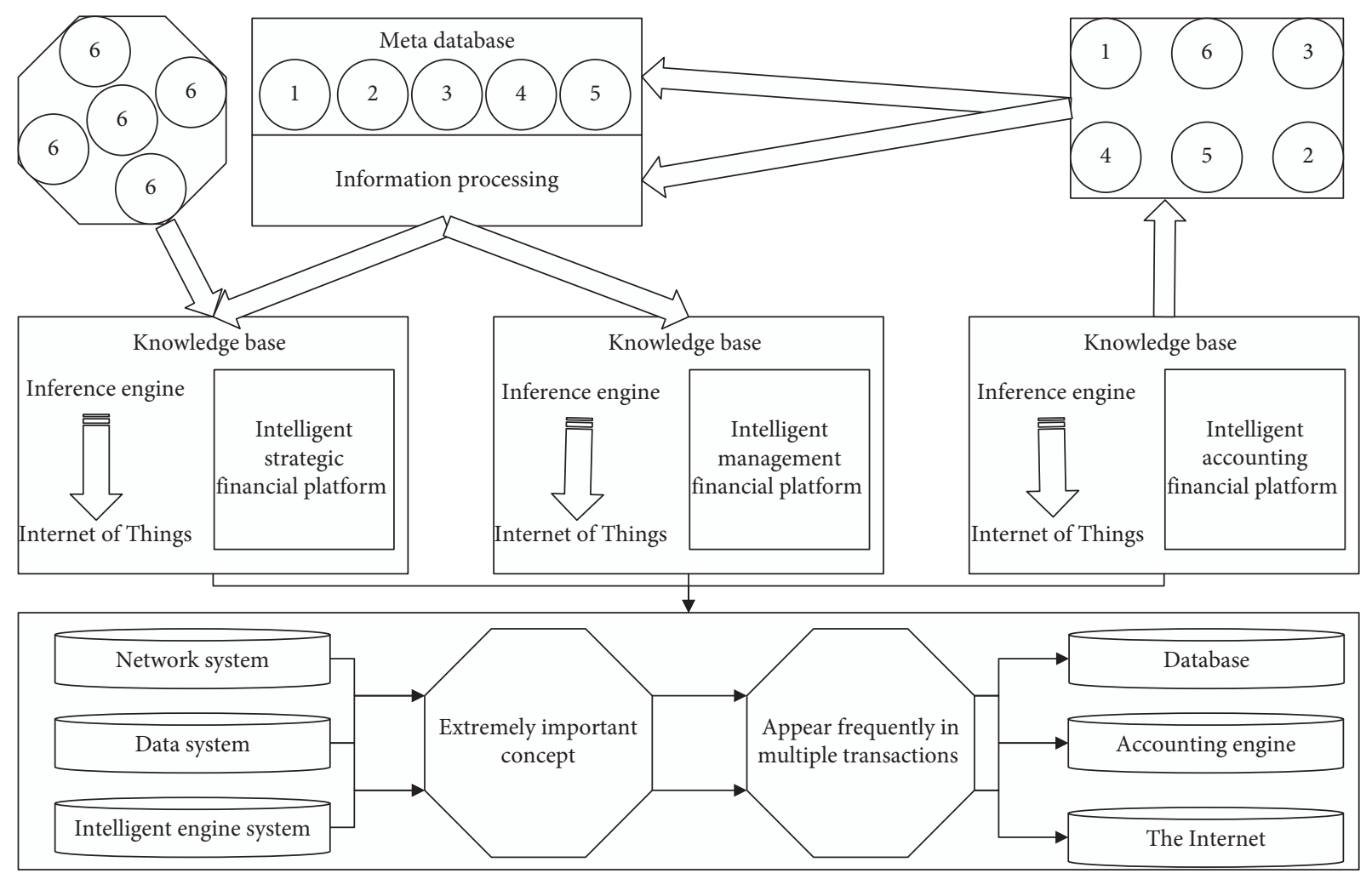

FIgURE 3: Smart financial system decision architecture.

profit, total operating income, total assets, total liabilities, owner's equity, gearing ratio, current ratio, and quick ratio, as shown in Figure 4.

Using data mining and big data crawler technology, it monitors the change process of enterprise risk factors in real time, evaluates the risk level by setting early warning lines for various risk states, sends early warning information to managers in real time, and gives suggestions for relevant risk warning measures. The financial risk early warning mechanism firstly constructs the benchmarking early warning evaluation index system and analyzes the index categories. The benchmarking early warning index system includes return on net assets, accounts receivable turnover rate, inventory turnover rate, operating income growth rate, net profit growth rate, i.e., comparing the excellent value, good value, average value, lower value, and worse value from four aspects: profitability, development ability, operation quality, debt risk. The overall evaluation and score of enterprise operation are finally given as shown in Figure 5.

Secondly, according to the expert opinion to give different weights to the indicators, a comprehensive evaluation of the evaluation indicator system, and can be based on the doubts of decision-makers can drill down layer by layer to any indicator and indicator formula of the secondary and tertiary composition and trend situation until the bottom of the data; finally, the intelligent generation of risk warning report and take corresponding countermeasures, the group company's risk attribution departments and affiliated units should track key risk indicators, judge and predict the changes of various risk indicators, and analyze the trend of risk development, and the breakthrough of risk limit should be reported to the general manager office of the group company, which will decide whether it can break through the warning and formulate countermeasures.

\subsection{Financial Management and Decision-Making Results.} First, the system does not provide enough support for the analysis function; each unit needs to develop a large number of reports for management purposes; after centralization, the relevant requirements are transferred from each unit to the headquarters; and the types of financial statements and analysis reports are complicated, so it is difficult to support the needs of each unit only by developing reports one by one at this stage, and it is difficult to interact with the information analysis of reports between the headquarters and 


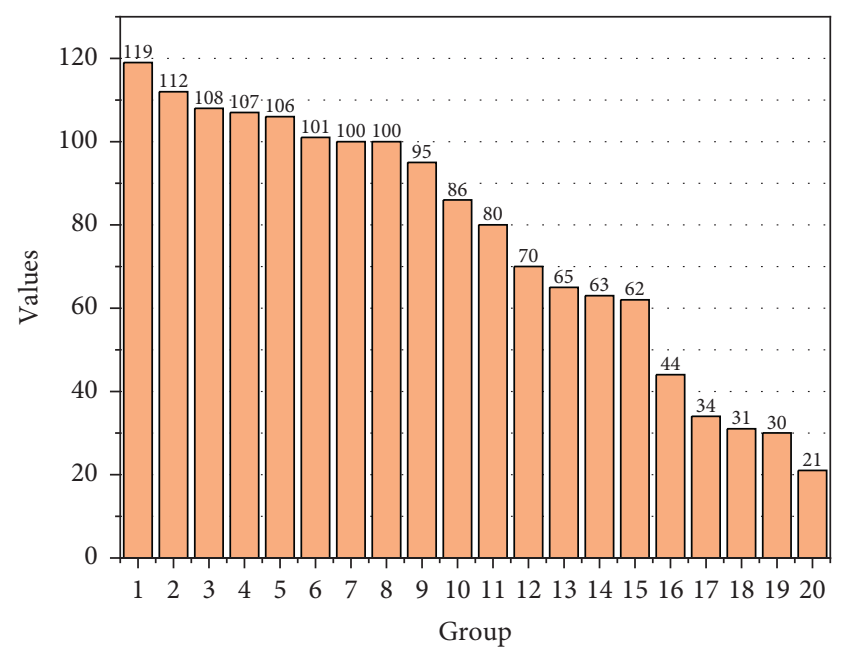

FIGURE 4: Group industry benchmarking ranking.

subunits, so the headquarters' financial control over subunits will be affected to a certain extent. The content involves nearly 30 industry indicators in five categories: profitability indicators, asset quality indicators, debt risk indicators, operating growth indicators, and supplementary indicators. To a certain extent, the financial control of the headquarters over the subunits will be affected. It is necessary to establish a unified platform of bank accounts for business processes and transaction data, allowing the information of both to be automatically matched and bound, thus ensuring that the source financial data is reliable and unique and using this as a starting point for closed-loop management of the whole process, such as approval, procurement, signing and execution of contracts, and acceptance and settlement, to realize the coordination and unification of the value creation process and the financial control process, as shown in Figure 6.

The problems of low interaction of ERP centralization on financial control are mainly insufficient support for analysis function, capital planning function to be improved, system optimization efficiency to be enhanced, and unclear system UIUE interaction. In the use of the system, the training of the grassroots staff of member enterprises should be strengthened, especially the learning and training of the staff who were originally familiar with only numerical operations in the system but not familiar with financial information, to prevent them from being unfamiliar with the information prompted by the system and unable to take effective measures promptly in response to the financial problems that arise and, at the same time, optimize the permission settings of each system of the content, without violating internal control and system security. In this case, the grassroots enterprises and grassroots financial personnel should be given more financial information query rights, to provide more valuable feedback to the grassroots financial information and enhance the rapid response capability of the grassroots. The main purpose is to record and centralize various financial data through the system, thus improving the efficiency of finance-related personnel and reducing human capital. However, although the centralized ERP

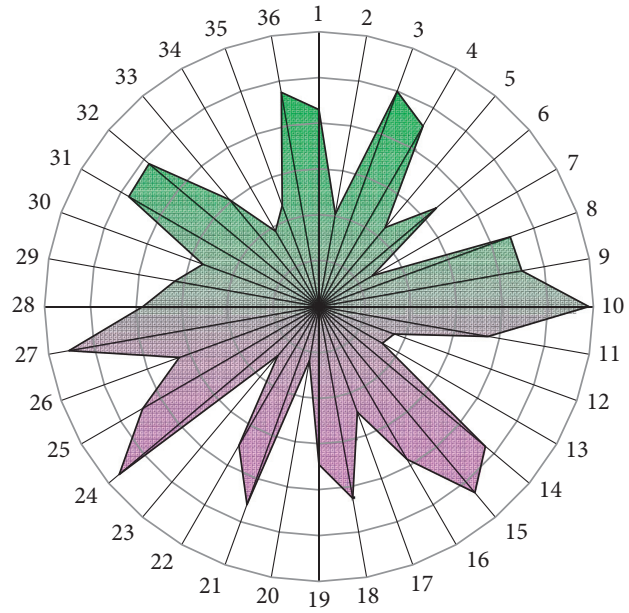

FIGURE 5: Overall evaluation of benchmarking early warning.

system has achieved a certain degree of human capital savings and accurate recording of large amounts of financial data, there are still many tasks that rely on the manual operations of finance staff. In addition, a large number of mechanical repetitive operations not only make the work of financial personnel mechanized and single, being unable to fully grasp the whole process of financial management, but also make it difficult to train professionals with high financial professionalism, by the methods of adverse selection, the enterprise selected a good program operating financial professional personnel, reduce the risk of the group enterprise financial management.

Comprehensively, the optimized financial shared service center can leave only the financial accounting specialists, technical staff, financial officers, etc. The entire organizational structure enables the grassroots staff to be separated from the low value-added work and put into the management, and the financial function is changed from financial accounting to management accounting. A comparison of organizational functions before and after optimization is shown in Figure 7.

R\&d investment reached more than 100 million yuan per year, maintaining a growth rate of more than $10 \%$, which accounted for $78 \%$ of the total cost in the same period. Therefore, precise control of this expenditure is also a core part of the design of this big data platform. However, the degree of precision and sharing of its financial control is relatively low, making it difficult to meet the richer financial control needs of the current group enterprises. Therefore, increasingly large group enterprises promote the leapfrog development of enterprise financial control through ERP centralization project, which strongly promotes the process of digital development. As a high-tech software enterprise, the group has many $R \& D$ projects and huge $R \& D$ investments. From the financial statements of recent years, the $R \& D$ investment reaches more than 100 million yuan of expenditure each year and maintains a growth rate of more than $10 \%$, and the expenditure accounts for $78 \%$ of the period expenses, so the accurate control of this budget is also the core of the blueprint design of this big data platform. 


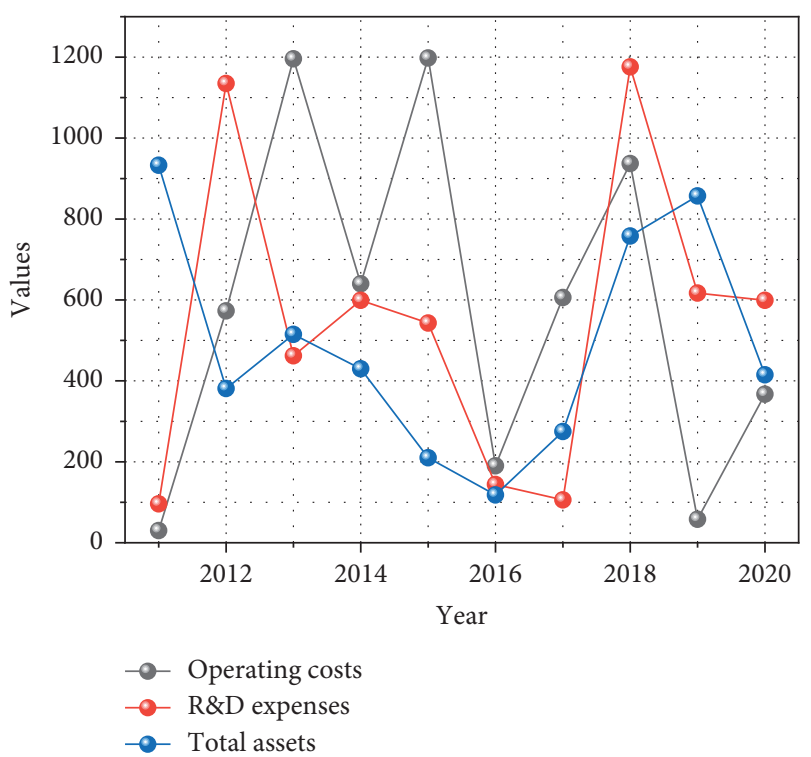

Figure 6: Group financial data.

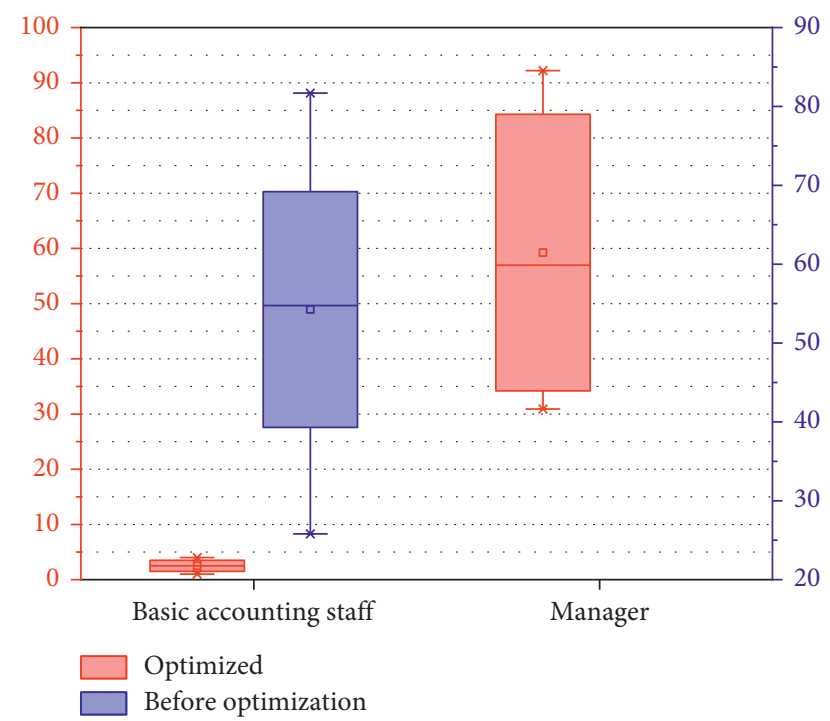

FIgURE 7: Comparison of organizational functions before and after optimization.

\section{Conclusion}

In the era of big data, financial management is the core element of the overall strategy of enterprises; enterprises can analyze a large amount of data to make more accurate decisions. Financial personnel must master more advanced technology to cope with the challenges brought by big data; financial managers and decision-makers of enterprises should reexamine and rethink the impact of big data on financial work and improve the decision-making ability to cope with environmental changes. This paper firstly elaborates the theories related to big data and analyzes the mechanism of mutual influence between big data and financial decision-making in four dimensions: how big data enhances the information base of prediction, how big data improves the relevance of decision-making, how big data builds new competitive advantages, and how big data promotes dynamic decision-making. Secondly, through the analysis of specific implementation cases of big data in financial decision-making of the group, the main focus is on the management difficulties and the direct effects and indirect benefits of solving problems through the big data platform. Good economic benefits achieved in the areas of personnel organization, procurement management, production quality, capital budgeting, and investment decision are compared with the previous ones. It can be concluded that in the era of big data, massive data can deeply serve the enterprise's decision-making, break the business and financial barriers, improve the efficiency and quality of decision-making, optimize the organizational structure and personnel, and enhance the prediction and early warning capability. The application of big data can become a key tool to assist financial decision-making and enhance enterprise value.

\section{Data Availability}

The data used to support the findings of this study are available from the author upon request.

\section{Conflicts of Interest}

The author has no conflicts of interest or personal relationships that could have appeared to influence the work reported in this paper.

\section{References}

[1] R. Chierici, A. Mazzucchelli, A. Garcia-Perez, and D. Vrontis, "Transforming big data into knowledge: the role of knowledge management practice," Management Decision, vol. 57, no. 8, pp. 1902-1922, 2019.

[2] K. Rybicka, "Usage of big data technology in controlling," Research in World Economy, vol. 10, no. 4, p. 92, 2019.

[3] V. Dhar, C. Sun, and P. Batra, "Transforming finance into vision: concurrent financial time series as convolutional nets," Big Data, vol. 7, no. 4, pp. 276-285, 2019.

[4] M. M. Hasan, J. Popp, and J. Oláh, "Current landscape and influence of big data on finance," Journal of Big Data, vol. 7, no. 1, pp. 1-17, 2020.

[5] T. M. T. Phung, Q. N. Tran, N. H. Nguyen, and T. H. Nguyen, "Financial decision-making power and risk taking," Economics Letters, vol. 206, no. 4, Article ID 109999, 2021.

[6] J. H. Fong, B. S. K. Koh, O. S. Mitchell, and S. Rohwedder, "Financial literacy and financial decision-making at older ages," Pacific-Basin Finance Journal, vol. 65, Article ID 101481, 2021.

[7] E. Ciola, A. Namatame, T. Lux, and S. H. Chen, "Financial sector bargaining power, aggregate growth and systemic risk," Journal of Economic Interaction and Coordination, vol. 15, no. 1, pp. 89-109, 2020.

[8] S. Shaw, Z. Rowland, and V. Machova, "Internet of Things smart devices, sustainable industrial big data, and artificial intelligence-based decision-making algorithms in cyberphysical system-based manufacturing," Economics, Management, and Financial Markets, vol. 16, no. 2, pp. 106-116, 2021. 
[9] B. K. Church, W. Jiang, X. Kuang, and A. Vitalis, "A dollar for a tree or a tree for a dollar? the behavioral effects of measurement basis on managers' csr investment decision," The Accounting Review, vol. 94, no. 5, pp. 117-137, 2019.

[10] \& N. Quzieva, "The issues of financial initiatinf export operations in Uzbekistan," International Finance and Accounting, no. 1, p. 14, 2019.

[11] J. Gao, T. Schott, X. Sun, and Y. Liu, "Heterogeneous effects of business collaboration on innovation in small enterprises: China compared to Brazil, Indonesia, Nigeria, and Thailand," Emerging Markets Finance and Trade, vol. 55, no. 4-6, pp. 795-808, 2019.

[12] N. Mc Donnell, E. Howley, and J. Duggan, "Dynamic virtual machine consolidation using a multi-agent system to optimise energy efficiency in cloud computing," Future Generation Computer Systems, vol. 108, pp. 288-301, 2020.

[13] O. Yuldashev, "Insurance of financial risks: problems and solutions," International Finance and Accounting, no. 2, p. 29, 2019.

[14] A. Qh, B. Jl, C. Jg, and C. Zq, "Systemic financial risk and macroeconomic activity in China," Journal of Economics and Business, vol. 102, pp. 57-63, 2019.

[15] Y. Zhou and H. Li, "Asset diversification and systemic risk in the financial system," Journal of Economic Interaction and Coordination, vol. 14, no. 2, pp. 247-272, 2019.

[16] E. Grant, "Big data-driven innovation, deep learning-assisted smart process planning, and product decision-making information systems in sustainable industry 4.0[J]," Economics, Management, and Financial Markets, vol. 16, no. 1, pp. 9-19, 2021.

[17] J. Ge, F. Wang, H. Sun, L. Fu, and M. Sun, "Research on the maturity of big data management capability of intelligent manufacturing enterprise," Systems Research and Behavioral Science, vol. 37, no. 4, pp. 646-662, 2020.

[18] W. Li, Q. Zhou, J. Ren, and S. Spector, "Data mining optimization model for financial management information system based on improved genetic algorithm," Information Systems and E-Business Management, vol. 18, no. 4, pp. 747-765, 2020.

[19] R. Davis, M. Vochozka, and J. Vrbka, "Industrial artificial intelligence, smart connected sensors, and big data-driven decision-making processes in Internet of Things-based realtime production logistics," Economics, Management, and Financial Markets, vol. 15, no. 3, pp. 9-15, 2020.

[20] O. M. Araz, T. M. Choi, D. L. Olson, and F. S. Salman, "Role of analytics for operational risk management in the era of big data," Decision Sciences, vol. 51, no. 6, pp. 1320-1346, 2020. 